\title{
The research of adding bacterial cellulose to improve the strength of long-fiber paper
}

\author{
Jing Yang ${ }^{1, a}$, Chuanshan Zhao ${ }^{2, b}$, Yifei Jiang ${ }^{3, c}$ and Wenjia Han ${ }^{4, d}$ \\ ${ }^{1}$ Key Laboratory of Pulp and Paper Science and Technology of Ministry of Education, QiLu \\ University of Technology, Jinan, Shandong Province,250353, China. \\ ${ }^{2}$ Key Laboratory of Pulp and Paper Science and Technology of Ministry of Education, QiLu \\ University of Technology, Jinan, Shandong Province,250353, China. \\ ${ }^{3}$ Key Laboratory of Pulp and Paper Science and Technology of Ministry of Education, QiLu \\ University of Technology, Jinan, Shandong Province,250353, China. \\ ${ }^{4}$ Key Laboratory of Pulp and Paper Science and Technology of Ministry of Education, QiLu \\ University of Technology, Jinan, Shandong Province,250353, China.

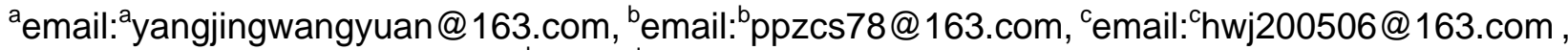 \\ demail: jiangyifei10432@163.com
}

Keywords: Bacterial Cellulose; Plant fiber; The beating degree; Physical properties

\begin{abstract}
BC (Bacterial Cellulose) is fermented by the bacteria and other microbes from wood vinegar. This paper studies using the well dispersed bacterial cellulose fibers which is modified by polypropylene with plant fibers to make paper .According to the changes of the physical properties indicators of the paper, we get the better ratio of furnish proportion and pulp freeness. Experiments show that when the bacteria fiber was $3 \%$, while the freeness of $40^{\circ} \mathrm{SR}$, the physical properties of the sheet reaches a maximum. Tensile index was $82.4 \mathrm{~N} \cdot \mathrm{m} / \mathrm{g}$ increase by $12.6 \%$ and a tear index of $11.4 \mathrm{mN} \bullet \mathrm{m} 2$ / g increase by $10.1 \%$, burst index of $6.05 \mathrm{kPa} \bullet \mathrm{m} 2$ / g improved $7.82 \%$.
\end{abstract}

\section{Introduction}

Bacterial cellulose is fermented by microorganisms, first reported [1]by Brown [3] in 1886. Bacterial cellulose is a cellulose component, which is generated by certain bacteria through the culture medium, as extracellular products [2]. Bacterial cellulose and plant fibers are macromolecular chain consisting of $\beta$-D- glucose linked together by $\beta$-1,4- glucosidic bonds, but the length of separate individual fibers of bacterial cellulose can not be separated intricate [3].

Bacterial cellulose as a new biological material has many characteristics and advantages. High purity [4]; Good air permeability permeable; High strength; Good Environmental adaptation[7]; The biosynthesis of bacterial cellulose is adjustable [8]. Bacterial cellulose to wheat straw, reed pulp and wood pulp were enhanced experimental studies have shown that physical strength of the sheet including tensile index 、 burst index v tear index has a very large increase [3]. Katsura Toru use dyeing bacterial cellulose to produce security paper, the identification of security paper and its surface strength is very high [4]. Sato Tatsuya use plant materials with different proportions of the bacterial cellulose to make a new type of thin printing paper [5]. We can see their existence in dictionary and vocabulary manuals, their advantage is to reduce paper weight and help improve the printing performance. In addition, bacterial cellulose can be added in the manufacture of carbon fiber board which can absorb gas, because of its high adhesion and high specific surface area, it not only can increase the amount of adsorption of carbon fiber, but can reduce the leakage of paper filler [6].

In this paper, the dispersed bacterial cellulose which is treated by mechanical homogenization, will be added to the plant fiber to make paper sheets, and then analysis the enhancement mechanism of the sheet by SEM. 


\section{Experimental}

\section{Materials}

i Paper stock: Canadian softwood bleached pulp; ii Additives: Bacterial cellulose (BC)、 Polyacrylamide

\section{Methods}

1)The treatment of bacterial cellulose

First, using the clean water wash the bacterial cellulose wet film, then tearing bacterial cellulose membrane into small pieces , then react with polyacrylamide to neutral[10] ,then the neutral BC is dispersed in the standard pulp sample fluffer ,the ratio of BC : water $=1: 10$ [9]. The standard pulp sample fluffer speed is $10000 \mathrm{r} / \mathrm{min}$, and treated $5 \mathrm{~min}$ at this speed. Finally using a rotary evaporator concentrate bacterial cellulose suspension after standard pulp sample fluffer treatment, finally determining the moisture of bacterial cellulose.

2)The treatment of softwood bleached pulp

Tearing the right amount of softwood pulp board into a certain size ,then using the tap water immersing the softwood pulp for 24 hours in a bucket, then the well- immersed the softwood pulp was beated by Wali beater for 30min, finally measuring the moisture of the beated and good drying softwood after 24h moisture balance. Then using the PFI refiner refining the pulp, during this process using control freeness tester controlling freeness at $40^{\circ} \mathrm{SR}$.

3)Papermaking and the physical properties measurement

The good dispersion and modified bacterial cellulose is mixed with softwood pup(freeness $40^{\circ}$ SR) according to different proportions ( $0 \%, 1 \%, 2 \%, 3 \%, 4 \%, 5 \%)$, and then using the automatic rotary screen papermaking machine to make 3 sheets for every proportion .The moisture of paper pattern should be balanced for 24 hours, finally measuring its quantitative respectively, tensile strength, tear index and burst index.

\section{Test results}

Adding a certain amount of bacterial cellulose, with the softwood pulp freeness rising, the physical strength of paper sheet showed a downward trend after the first increase.
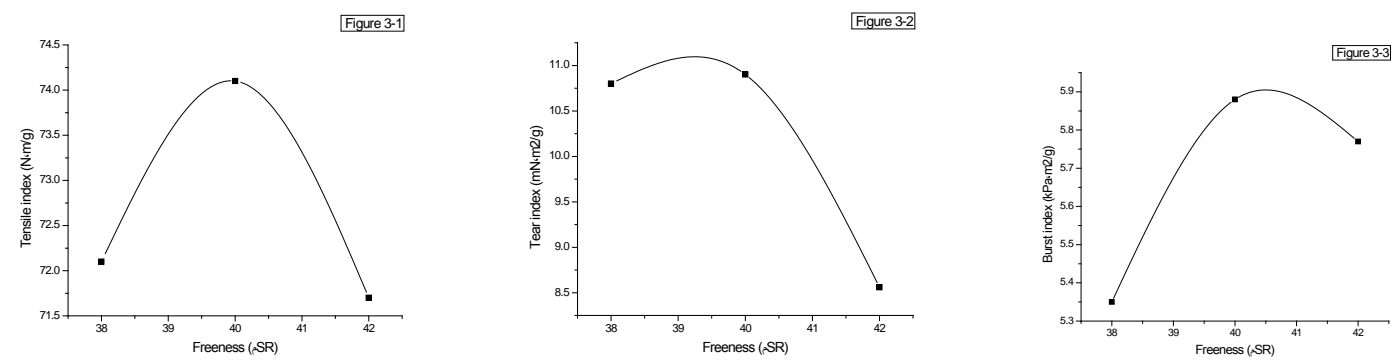

(a):the beating impact of the bursting index; (b):the beating impact of tensile index; (c): the beating impact of tear index.

Fig.1. Effect of beating on mechanical strength properties of softwood

From Figure 1(a), it can be observed with the increase of freeness, physical tensile index showed a downward trend after the first increase. However, when the beating degree of $40^{\circ} \mathrm{SR}$, tensile index sheet reaches a maximum of $74.1 \mathrm{~N} \cdot \mathrm{m} / \mathrm{g}$. It can be clearly seen from Figure 1 (b), at the time of softwood pulp freeness $40^{\circ} \mathrm{SR}$, the tear index reached its maximum of $10.9 \mathrm{mN} \cdot \mathrm{m} 2 / \mathrm{g}$. From this point, with the increasing of beating degree, the tear index decrease. We can clearly see from Figure 1 (c), with the increases of pulp freeness, burst index show a decline after rising. We can know that the burst index is up to $5.88 \mathrm{kPa} \cdot \mathrm{m} 2 / \mathrm{g}$ at the freeness of $40^{\circ} \mathrm{SR}$.

Effect of the amount of modified bacterial cellulose on mechanical strength 

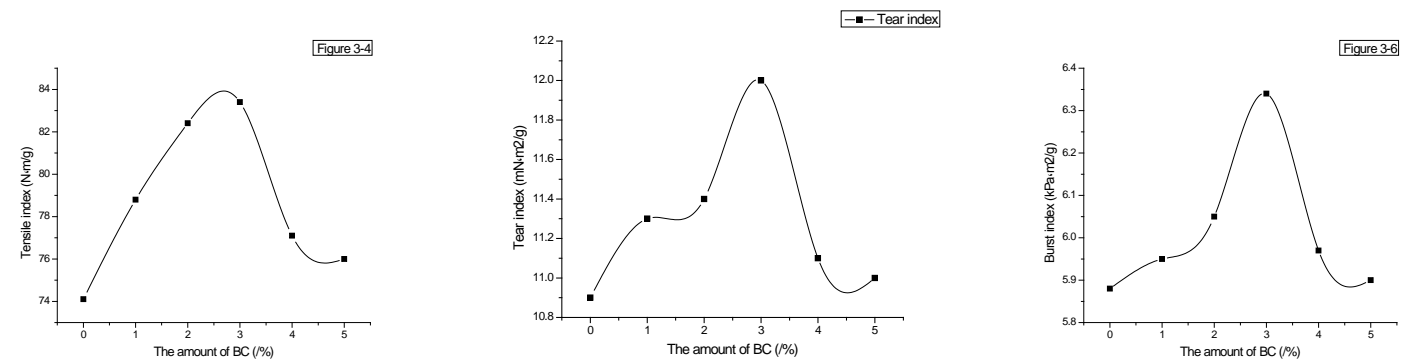

(d):the effect of the amount of modified bacterial cellulose on tensile strength ; (e): the effect of the amount of modified bacterial cellulose on tear index; (f):the effect of the amount of modified bacterial cellulose on broken index.

Fig.2. Effect of the amount of modified bacterial cellulose on mechanical strength

As is shown in Figure 2 (d), adding modified bacterial cellulose in papermaking process when wood pulp is at $40^{\circ} \mathrm{SR}$, with the increase of modified bacteria cellulose ,the tensile index showed the rising trend after a decline. However, when added in an amount of $3 \%$, it reached a maximum of 83.4N • m / g. Similarly, we can observe from Figure2 (e), with the increasing amount of modified bacterial cellulose, tear index showed the rising trend after a decline. When modified bacterial cellulose reaches $3 \%$, it reached a maximum of $12.0 \mathrm{mN} \cdot \mathrm{m} 2 / \mathrm{g}$. From Figure 2 (f) it can be clearly observed that with increasing amounts of modified bacterial cellulose, burst index sheet rises slowly at first and then increase rapidly to reach a certain point and then show a declining trend, the highest point value was $6.34 \mathrm{kPa} \cdot \mathrm{m} 2 / \mathrm{g}$ at the moment of bacterial cellulose was $3 \%$. Overall, while modified bacterial cellulose obtained in an amount of 3\%, the physical properties of the sheet reaches the maximum, tensile index increased by $12.6 \%$, tear index increased by $10.1 \%$, bursting index increased by $7.82 \%$.

\section{SEM analysis}
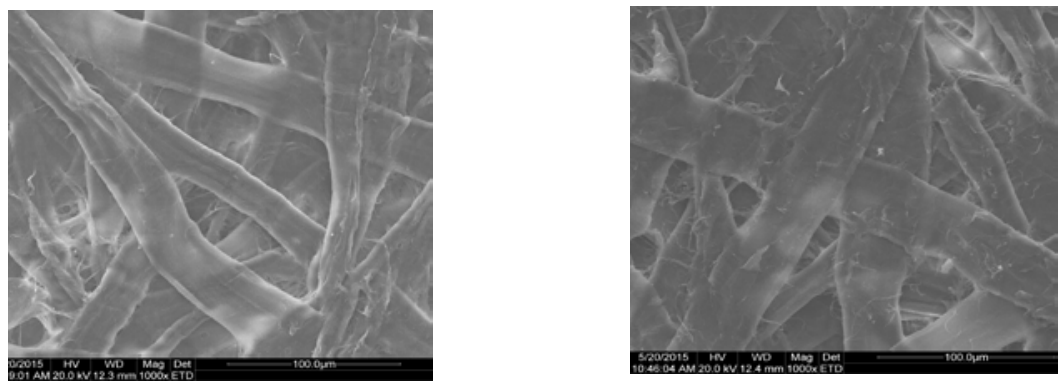

(g) 40. SR paper of softwood pulp SEM (× 1000); (h) adding $1 \%$ of modified bacteria cellulose SEM ( $\times$ 1000)

Fig.3. SEM analysis

The modified fibers are playing a bridging role to plant fibers. And because hydrogen bonds between the fibers of modified bacteria is opened, then the free hydroxyl groups on the molecule constantly are exposed, they will have more chance to link hydrogen bonds with plant fibers, the binding force between fibers will also continue to increase, so the physical indicators of the sheet will Adsorbed on the surface of plant fiber. In addition, the figure can also be found when adding small amounts of modified bacterial cellulose, we can clearly see the bindings between plant fibers and bacterial cellulose, but with the added amount of modified bacterial cellulose is gradually increase in plant fiber are becoming increasingly blurred.

\section{Conclusion}

Different amounts of modified bacterial cellulose pulp mixed with softwood fibers of different freeness for papermaking, and then the experiments is detection of the physical properties (tensile 
index, burst index, tear index and other physical properties),the modified bacterial cellulose obtained in an amount of 3\%, the physical properties of the sheet reaches the maximum, tensile index increased by $12.6 \%$, tear index increased by $10.1 \%$, bursting index increased by $7.82 \%$.Observing the pattern of scanning electron microscope image, then we can analysis that the modified bacterial cellulose can play a similar "bridging" role between the plant fibers, so it will have a certain degree of improvement of physical properties.

\section{References}

[1] Jia Shiru bacterial cellulose biosynthesis and its application [J] Chemical Technology Market, 2001, (2): 21-23.

[2] Sun Zhao Xia, Zhang Su wind, Meixing Xian. Structure and Properties and Application Research Progress of Bacterial Cellulose [J]. Hubei paper, 2013, (3). DOI:10.3969/j.issn.10069631.2013.03.004.

[3] Ross P, etal. Cellulose biosynthesis and function in bacteria [J].Microbiological Reviews, 1991, 55(1): 35-58.

[4] Jia Shiru, Europe Hong Yu, Marcia, and other preliminary studies of bacterial cellulose structure and properties of [J] Cellulose Science and Technology, 2002, 10 (3): 25-30.

[5] Katsura Toru, Okafuro Kenichi. Forgery-preventive paper : JP, 6313297A2[P]. 1994.

[6] Sato Tatsuya, Hibino Yoshihiko, Thin Layer Printing Paper : JP, 11061678A2[P]. 1999.

[7] Marcia, WANG Rui-ming, off Fengmei, other bacterial cellulose and its application in the paper industry [J] Heilongjiang paper, 2003,31 (3): 3-4.

[8] Ye Xiaochun affect water retention value of pulp and paper properties and a paper copy performance [J] Forest Products Industry, 1994, 21 (4): 20-23.

[9] repair Huijuan, Li Jinbao new biological materials and paper - Bacterial Cellulose [J] paper and paper, 2002, (5): 71-72.

[10] Li Jinbao, repair Huijuan, Wang Zhijie BC [10] - new biological paper intensifier [J] Shaanxi University of Science and Technology: Natural Science Edition, 2007, (3): 9-12. 